\title{
Influence of Skull Fracture on Traumatic Brain Injury Risk Induced by Blunt Impact
}

\author{
Lihai Ren ${ }^{1,2}$, Dangdang Wang ${ }^{2}$, Xi Liu ${ }^{1,2, *}$, Huili Yu ${ }^{3}$, Chengyue Jiang ${ }^{2}$ and Yuanzhi Hu ${ }^{1,2}$ \\ 1 State Key Laboratory of Vehicle NVH and Safety Technology, China Automotive Engineering Reasearch \\ Institute Co., Ltd. and Chongqing Chang'An Automobile Co., Ltd., Chongqing 401122, China; \\ lihai.ren@cqut.edu.cn (L.R.); yuanzhihu@cqut.edu.cn (Y.H.) \\ 2 Key Laboratory of Advanced Manufacturing Technology for Automobile Parts, Ministry of Education, \\ Chongqing University of Technology, Chongqing 400054, China; wangdangdang@2018.cqut.edu.cn (D.W.); \\ jiangchengyue@cqut.edu.cn (C.J.) \\ 3 Chang'An Automobile Co., Ltd., Chongqing 400023, China; yuhl@changan.com.cn \\ * Correspondence: liuxi@cqut.edu.cn
}

Received: 28 February 2020; Accepted: 30 March 2020; Published: 1 April 2020

\begin{abstract}
This study is aimed at investigating the influence of skull fractures on traumatic brain injury induced by blunt impact via numerous studies of head-ground impacts. First, finite element (FE) damage modeling was implemented in the skull of the Total HUman Model for Safety (THUMS), and the skull fracture prediction performance was validated against a head-ground impact experiment. Then, the original head model of the THUMS was assigned as the control model without skull element damage modeling. Eighteen (18) head-ground impact models were established using these two FE head models, with three head impact locations (frontal, parietal, and occipital regions) and three impact velocities $(25,35$, and $45 \mathrm{~km} / \mathrm{h})$. The predicted maximum principal strain and cumulative strain damage measure of the brain tissue were employed to evaluate the effect of skull fracture on the cerebral contusion and diffuse brain injury risks, respectively. Simulation results showed that the skull fracture could reduce the risk of diffuse brain injury risk under medium and high velocities significantly, while it could increase the risk of brain contusion under high-impact velocity.
\end{abstract}

Keywords: blunt impact; head finite element model; skull fracture; traumatic brain injury

\section{Introduction}

Road traffic collisions (RTCs) have become one of the most severe worldwide public health problems, and approximately 5 million people are injured and 1.2 million die from RTCs every year [1]. In China, approximately 200,000 RTCs occur annually, which leads to more than 200,000 injuries every year [2]. One of the main causes of the casualty in RTCs is severe traumatic brain injury (TBI) caused by head blunt impacts [3-5].

Blunt-impact head injuries of RTCs mainly include skull fracture and TBI [6,7]. The patterns of skull fracture depending on the initial head impact location (or direction), which can be divided into three main groups: anterior, lateral, and posterior, that is, frontal, lateral-parietal, and occipital, respectively [8-10]. According to the distribution of injury, TBIs can be divided into focal brain injuries and diffuse brain injuries (DBIs) [11-13]. Focal brain injuries usually lead to loss of partial brain function with contusions, intracranial hematomas, and so on $[4,14]$. DBIs include mild concussion, moderate concussion with brief coma, and diffuse axonal injury with long-term coma or death $[12,13]$. As demonstrated by real-world RTC data, approximately $50 \%$ and $25.8 \%$ of patients suffered from skull fractures [14] and cerebral contusions [3], respectively, while DBIs were found in approximately $35 \%$ of severe-head-injury-related deaths [11]. 
Even if numerous studies have been conducted to investigate mechanisms of blunt-impact head injury, the effect of skull fracture on TBIs has not been clearly understood. However, there is a significant correlation between skull fractures and TBIs $[3,4,14]$. Partial impact energy could be absorbed during the skull fractures, which could possibly reduce the energy transferred to the brain tissue [15]. Based on an investigation of the relationship between skull fractures and TBIs from 500 RTC-related head injuries, Yavuz et al. [3] indicated that the presence of skull fractures could lower the incidence of TBIs, while TBI-related patients without skull fractures are more likely to die in traffic accidents than those with skull fractures based on an investigation of 54 cases with RTC-related head injuries by Carson et al. [14]. However, because of the complexity of traffic accident conditions, the physiological structure of the human head, and the pathology of brain injuries, the mechanism of the influence of skull fractures on blunt impact is still unclear.

Therefore, finite element (FE) head-ground impact models were established, referring to an existing head-ground impact experiment. The objective of this study is to investigate the influence of skull fractures on the intracranial strain response of brain tissue associated with the brain contusion and DBIs following the head-ground impacts.

\section{Methods}

\subsection{Head FE Model}

A 50th-percentile adult human head FE model (HFEM), extracted from the Total HUman Model for Safety (THMUS, Toyota Central R\&D Laboratories, Nagakute, Japan; version 4.01) modeled by LS-DYNA software (version 971), was employed in this study. The most essential anatomical features of the human head are represented, including the scalp, skull, epidural, cerebrospinal fluid, cerebral white matter, cerebral gray matter, cerebellum white matter, cerebellum gray matter, brain stem, and brain chamber (Figure 1). The skull was modeled as a sandwich structure consisting of two layers of shell elements and one layer of solid elements, which presented the outer plastic material of the table of the compact bone and the inner elastic-viscoplastic material of the spongy bone, respectively (Figure 2). The Total HUman Model for Safety (THUMS)-head FE model has been extensively validated [16] and is widely used in the research field of the blunt impact-head injuries [17-21]. The detailed modeling method and parameters of the THUMS-head FE model are referenced in Toyota Motor Corporation documentation [16] and Kimpara et al. [22].

FE damage modeling was implemented in the skull of the original THUMS-head FE model in order to predict the possible skull fracture under head blunt impact. According to the published studies associated with skull fracture behavior and the following head impact loading conditions employed in this study [23-25], material properties of the skull element damage modeling were assigned as yield stresses of 95.88 and $4.794 \mathrm{MPa}$ and plastic strain failure thresholds of 0.02 and 0.006 , respectively, for compact bone and spongy bone.

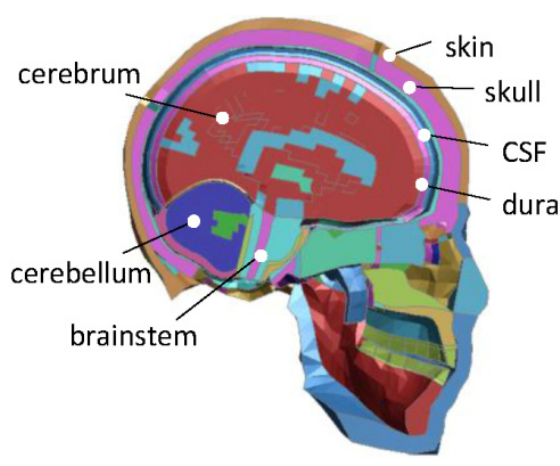

Figure 1. THUMS-head FE model. 


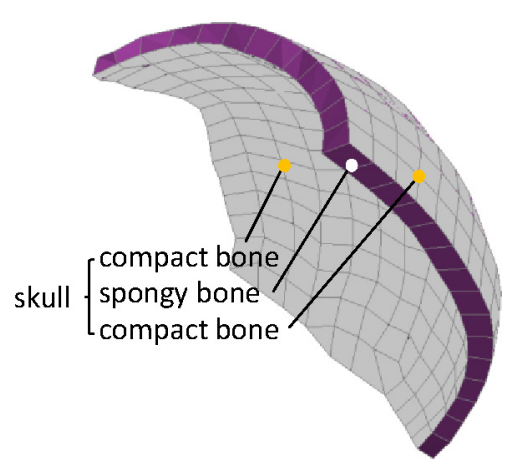

Figure 2. Three-layer structures of skull.

\subsection{Skull Fracture Prediction Performance Validation}

The skull fracture prediction performance of the improved THUMS-head FE model was evaluated via the reconstruction of an existing head-ground impact experiment carried out by Jiang et al. [26]. The original experimental equipment included an accelerator, asphalt road model, a high-speed camera, and an accelerating device (Figure 3). As demonstrated in the referenced study, the cadaver head was wrapped with white clothes and attached to the accelerating device by several seatbelts; the head was then accelerated to $44.1 \mathrm{~km} / \mathrm{h}$ and impacted against the oblique ground at the occipital region; finally, the time history of the head acceleration at the foramen magnum region and the skull fracture were obtained through data acquisition system and CT scanner, respectively.

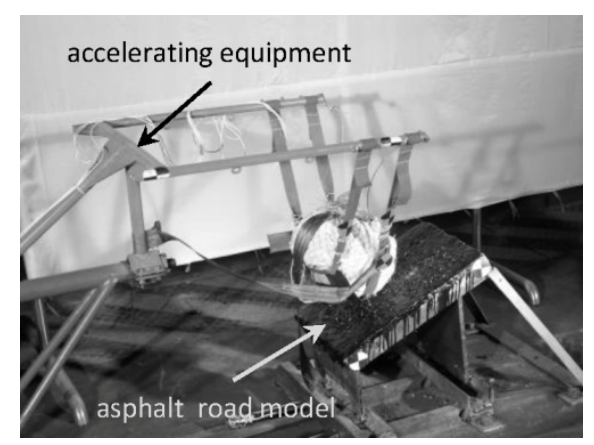

Figure 3. Head-ground impact experiment.

A FE simulation model was established according to the referenced experimental data in LS-DYNA software, as shown in Figure 4. The ground with an asphalt surface (15 mm thick) and a concrete roadbed (45 mm thick) was modeled as an equivalent road using linear elastic solid elements [27] (Figure 4). The material parameters of the FE road model that have been applied in the pedestrian head-ground impact simulations were assigned [28] (Table 1). An initial velocity of $44.1 \mathrm{~km} / \mathrm{h}$ was assigned to the head model, and the key word of *AUTOMATIC_CONTACT_SURFACE_TO_SURFACE was employed for the head-ground contact with a friction coefficient of $0.58[29,30]$. 


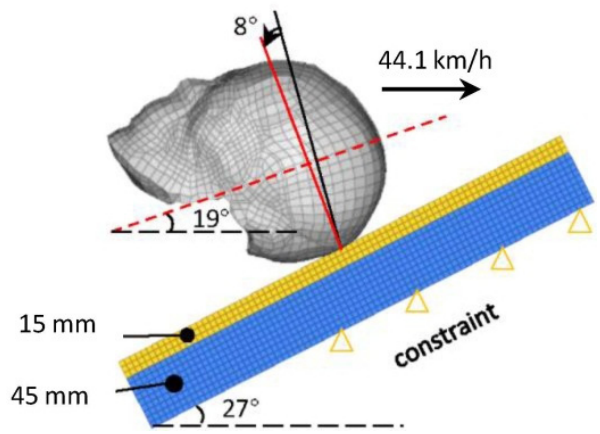

Figure 4. Setup of head-ground impact FE model. Black solid line is the parallel line of the vertical plane, and red solid line is that of the brain sagittal plane after rotating $8^{\circ}$. Red dotted line is located in the coronal plane of the head. The size of the ground is $500 \times 500 \times 60 \mathrm{~mm}$.

Table 1. Material properties of asphalt concrete road FE model.

\begin{tabular}{ccccc}
\hline Structure & $\begin{array}{c}\text { Density/ } \\
\left(\mathbf{k g} / \mathbf{m}^{\mathbf{3}}\right)\end{array}$ & $\begin{array}{c}\text { Elasticity } \\
\text { Modulus } \mathbf{( M P a )}\end{array}$ & Poisson's Ratio & Material Model \\
\hline asphalt & 1600 & 5400 & 0.35 & linear elastic \\
roadbed & 1600 & 9300 & 0.35 & linear elastic \\
\hline
\end{tabular}

The predicted skull fracture and head acceleration at the foramen magnum are illustrated in Figures 5 and 6, respectively. The skull fracture predicted at the head impact location (occipital region) correlated well with the corresponding skull fracture observed in the referenced experiment (Figure 5). As illustrated in Figure 6, the predicted time history of the resultant head acceleration was also well consistent with the referenced experimental data, with peak values of 307.79 and $281.32 \mathrm{~g}$. Despite the missed prediction of the skull fracture at the temporoparietal region, the current head model indeed applied for the following simulation.

(A)

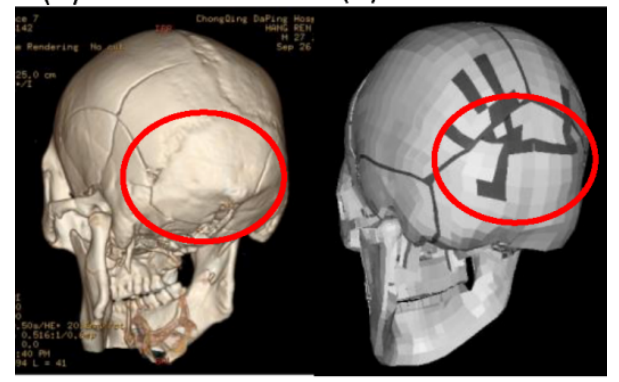

Figure 5. Comparison of skull fracture patterns between the (A) experiment and (B) simulation.

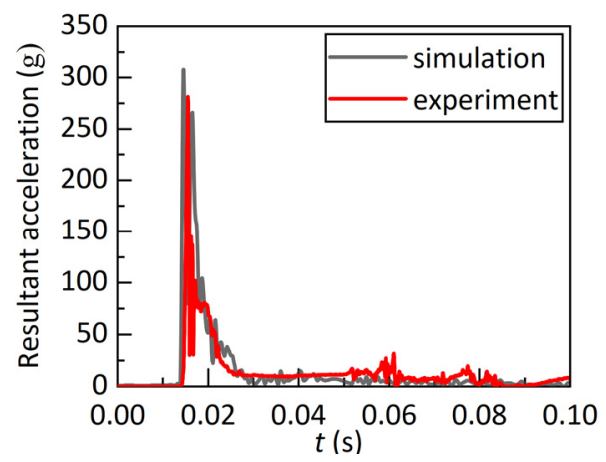

Figure 6. Comparison of head resultant acceleration between the experiment and simulation. 


\subsection{Head-Ground Impact Simulation Matrix}

A matrix of head-ground impact simulation was performed using the current improved THUMS-head FE model and the original THUMS-head FE model for a quantitative comparison of the predicted intracranial dynamic responses under three head impact locations: frontal, lateral-parietal, and occipital regions. Here, the current improved THUMS-head FE model was assigned as the fracture model, while the original THUMS-head FE model was assigned as the non-fracture model. Three head impact velocities, 25,35 , and $45 \mathrm{~km} / \mathrm{h}$ (low, medium, and high) were assigned to each model of three impact locations. Thus, a total of 18 simulations were performed. The detailed boundary conditions are illustrated in Figure 7.

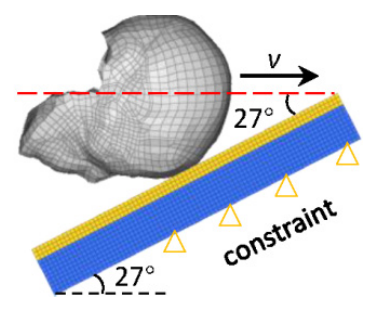

(a) frontal impact

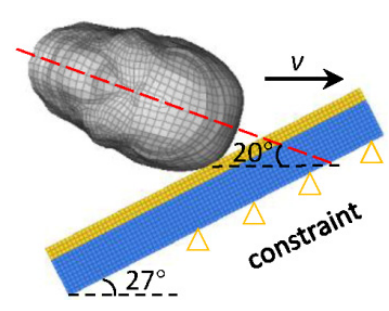

(b) parietal impact

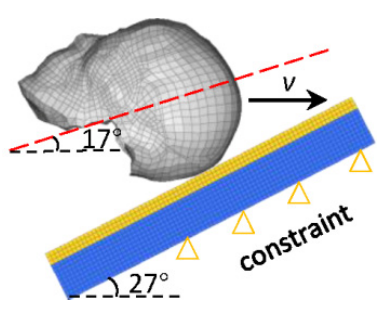

(c) occipital impact

Figure 7. Illustrations of head-ground model for three impact locations. Red dotted line is located in the coronal plane of the head for (a) and (c) and in the mid-sagittal plane of the head for (b).

To simulate the same risk of brain injuries in models of three impact locations at the same impact velocity, different impact angles of the head were designed. Here, the Brain Injury Criteria (BrIC) were calculated.

The BrIC was developed by Takhounts et al. [31], based on the mechanism of the head rotational motion for brain injuries. Furthermore, angular velocity is the only component of the BrIC. Therefore, angular velocities of the head model in three axes were extracted, and BrIC were calculated to assess the risk of brain injury. BrIC are expressed as follows:

$$
B r I C=\sqrt{\left(\frac{\omega_{x}}{\omega_{x C}}\right)^{2}+\left(\frac{\omega_{y}}{\omega_{y C}}\right)^{2}+\left(\frac{\omega_{z}}{\omega_{z C}}\right)^{2}}
$$

where $\omega_{x}, \omega_{y}$, and $\omega_{z}$ are maximum angular velocities about the $X_{-}, Y_{-}$, and Z-axes respectively; $\omega_{x}$, $\omega_{y C}$, and $\omega_{z C}$ are the critical angular velocities in their respective directions, which are 66.25, 56.45, and $42.87 \mathrm{rad} / \mathrm{s}$ [31]. The BrIC values at 50\% risk of the Abbreviated Injury Scale (AIS) 2+, and $4+$ brain injuries are 0.5 and 1 , respectively [31].

\subsection{Intracranial Dynamic Response and Data Analysis}

\subsubsection{Intracranial Dynamic Responses}

The maximum principal strain (MPS) and cumulative strain damage measure (CSDM) were calculated and assigned as the injury indexes for the proper prediction of cerebral contusion and diffuse brain injury, respectively. The MPS has been suggested as an efficient injury index of cerebral contusion under blunt impact [32,33]. In this study, 18 elements in a cube region in which the maximum strain response appeared in the brain impact region were selected for a calculation of average peak MPS. The CSDM has long been used as an essential injury index for the prediction of the DBI caused by brain tissue deformation [34,35], and is defined as the volume percentage of elements with the peak MPS exceeding a certain strain threshold for the target regions, as follows:

$$
C S D M=\frac{V\left(\varepsilon_{1} \geq \varepsilon_{c}\right)}{V}
$$


where $\varepsilon_{1}$ is the elemental peak MPS and $\varepsilon_{\mathcal{c}}$ the defined strain threshold. The white matter of the cerebrum and brainstem was selected as the target regions for the CSDM calculation, and the current strain threshold was set to 0.15 [34-36].

\subsubsection{Data Analysis}

Differences in average peak MPS and CSDM between the fracture and non-fracture models were quantitatively analyzed by one-way analysis of variance (one-way ANOVA, Office Excel 2016). First, the MPS time history curves of the selected 18 elements were obtained from each simulation; then, one-way ANOVA was performed to evaluate the difference between the average peak MPS of the two head models under the same impact conditions. The difference between the two groups of CSDM predicted by the corresponding two head models was also evaluated by using the one-way ANOVA. The F-test was conducted to determine whether the skull fracture had a statistically meaningful effect on the average peak MPS and CSDM results: When the $p$-value is lower than 0.05 , it can be said that a significant effect exists; otherwise, there is no such significant effect.

\section{Results}

\subsection{Skull Fractures and Head Kinematic Responses}

Figure 8 shows that varying degrees of fracture are predicted in these impact regions with different head impact velocities. In general, there were distinct differences in fracture patterns in different skull regions. For $25 \mathrm{~km} / \mathrm{h}$, only small linear skull fractures were predicted in the frontal and occipital regions (Figure 8a,g, respectively); but no fracture was predicted in the parietal region (Figure 8d). Severe linear skull fractures and multiple skull fractures were predicted in the frontal and occipital regions at 35 and $45 \mathrm{~km} / \mathrm{h}$, respectively (Figure $8 \mathrm{~b}, \mathrm{c}, \mathrm{h}, \mathrm{i}$ ). However, severely depressed skull fractures appeared in the parietal region with the head impact velocities of 35 and $45 \mathrm{~km} / \mathrm{h}$ (Figure $8 \mathrm{e}, \mathrm{f}$ ).

(a)

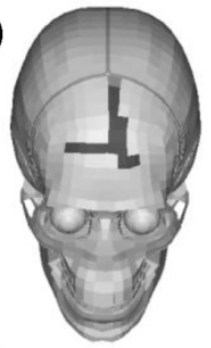

(d)

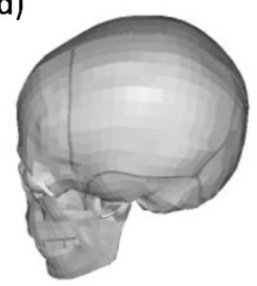

(g)

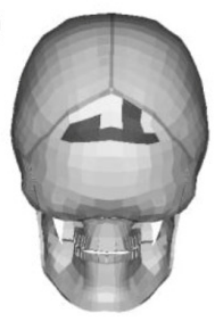

(b)

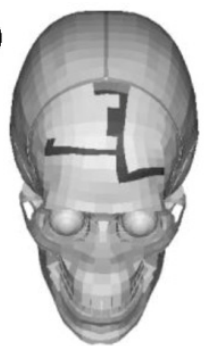

(e)

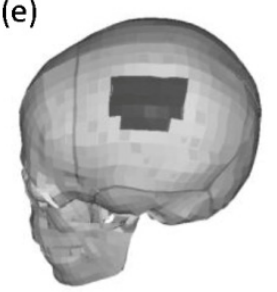

(h)

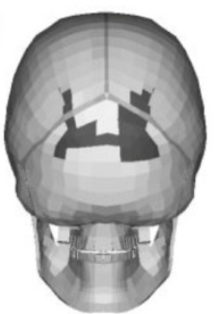

(c)

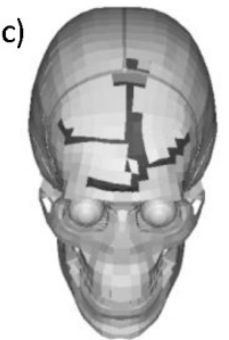

(f)

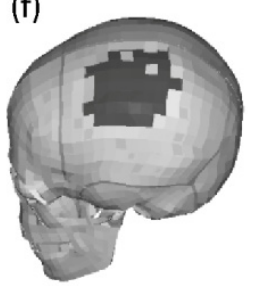

(i)

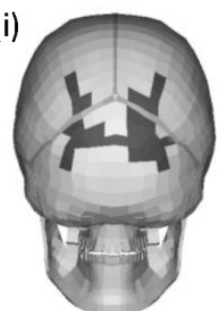

Figure 8. Fracture patterns of head fracture model for three locations under three impact velocities. (a-c) Frontal impact, (d-f) parietal impact, and (g-i) occipital impact; the impact velocities are 25, 35, $45 \mathrm{~km} / \mathrm{h}$ from left to right, respectively; the skull fracture is represented in black. 
Figure 9 shows the comparison of the resultant acceleration (filter of $1000 \mathrm{~Hz}$ ) with a parietal impact contrecoup side between fracture and non-fracture models at $35 \mathrm{~km} / \mathrm{h}$. The predicted resultant acceleration of the fracture model was $19.8 \%$ lower than the corresponding value of the non-fracture model.

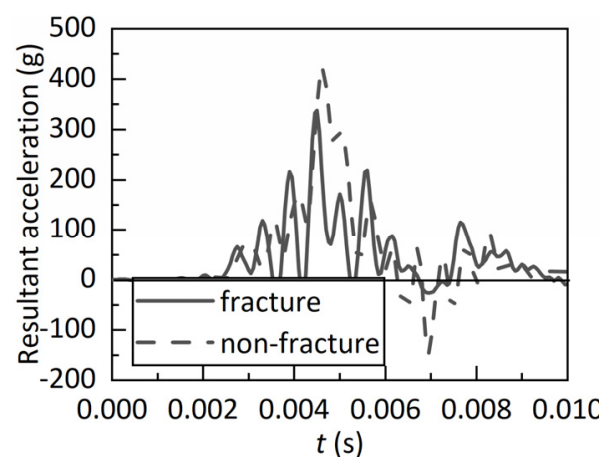

Figure 9. Comparison of resultant acceleration (filter of $1000 \mathrm{~Hz}$ ) with parietal impact contrecoup side between fracture and non-fracture models at $35 \mathrm{~km} / \mathrm{h}$.

Figure 10 shows the BrIC of the non-fracture model for three impact locations under three impact velocities. The calculated average BrIC values of the three impacts at 25,35 , and $45 \mathrm{~km} / \mathrm{h}$ were 0.78 , 1.13, and 1.41, respectively. According to the BrIC risk curves of brain injuries [29], the AIS 2+ injuries could be realized in all simulations.

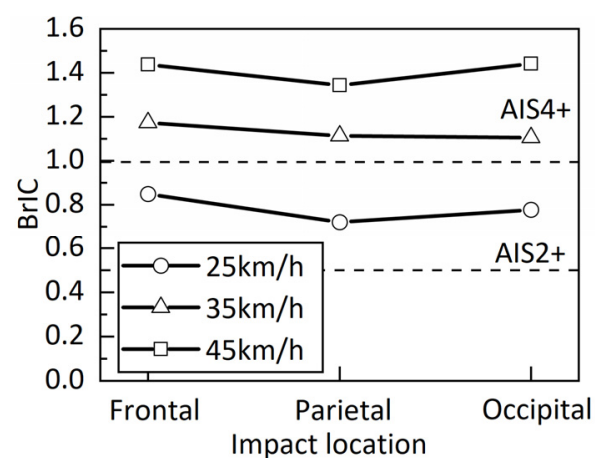

Figure 10. BrIC of the non-fracture model for three impacts at three impact velocities. Dotted lines are $50 \%$ risk of AIS $2+$ and AIS 4+ brain injuries from the bottom up.

\subsection{Strain Responses of Brain Tissue}

Figure 11 shows the MPS contour for occipital impacts at three impact velocities. At medium and high impact velocities, the brain of the fracture model exhibited severe extrusion deformation, which resulted in relatively higher MPS responses (Figure $11 \mathrm{~b}, \mathrm{c}$ ).

The average peak MPS values of the selected elements of the fracture model are lower than the corresponding values of the non-fracture model at 25 and $35 \mathrm{~km} / \mathrm{h}$, as illustrated in Figure 12. For $25 \mathrm{~km} / \mathrm{h}$, compared with MPS values of the non-fracture model, corresponding values of the fracture model were $45.7 \%, 0.3 \%$, and $38.0 \%$ lower, for the frontal, parietal, and occipital impacts, respectively. Similarly, for $35 \mathrm{~km} / \mathrm{h}$, the MPS values of the fracture model were $1.5 \%, 4.5 \%$, and $4.5 \%$ lower than the corresponding values of the non-fracture model, respectively. Inversely, the average peak MPS values of the fracture model were generally higher than the corresponding values of the non-fracture model at $45 \mathrm{~km} / \mathrm{h}$. For $45 \mathrm{~km} / \mathrm{h}$, compared with MPS values of the non-fracture model, corresponding values of the fracture model were $6.7 \%,-22.8 \%$, and $16.1 \%$ higher for the frontal, parietal, and occipital impacts, respectively. 
As shown in Figure 12, there was a significant effect of the skull fracture on average MPS values; except for the parietal impact at $25 \mathrm{~km} / \mathrm{h}(p=0.975)$, the $p$-values were less than 0.01 for frontal and occipital impacts. However, there was no significant effect of skull fractures on the average MPS values for all simulation at $35 \mathrm{~km} / \mathrm{h}(p>0.05)$. Inversely, significant effects were observed for all simulations at $45 \mathrm{~km} / \mathrm{h}$ with $p$-values less than 0.01 .
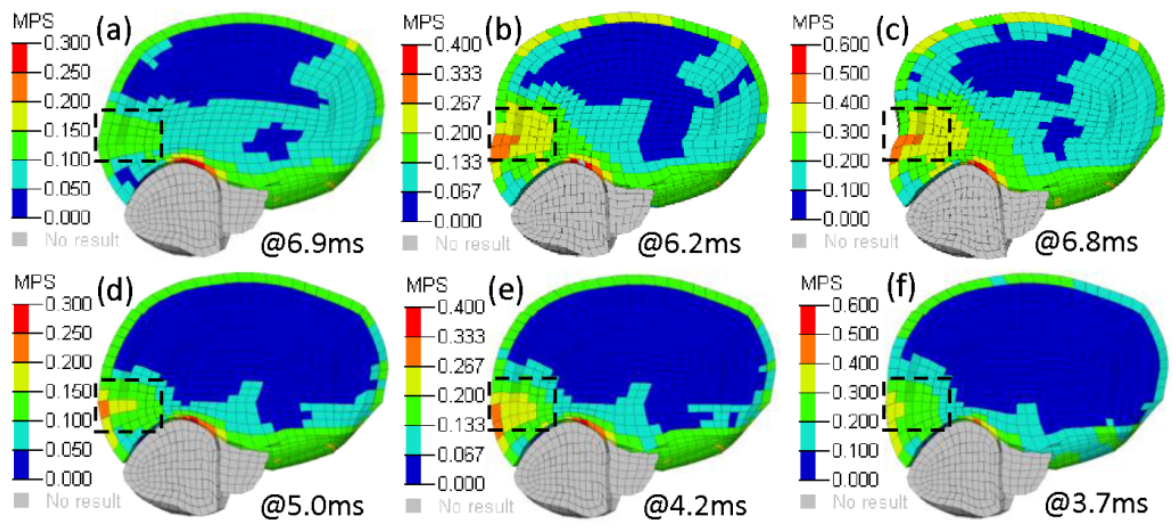

Figure 11. MPS contour for occipital impacts at three impact velocities. (a-c) Fracture model, (d-f) non-fracture model; impact velocities are 25,35 , and $45 \mathrm{~km} / \mathrm{h}$ from left to right; dotted line box is at the peak MPS region of impact.

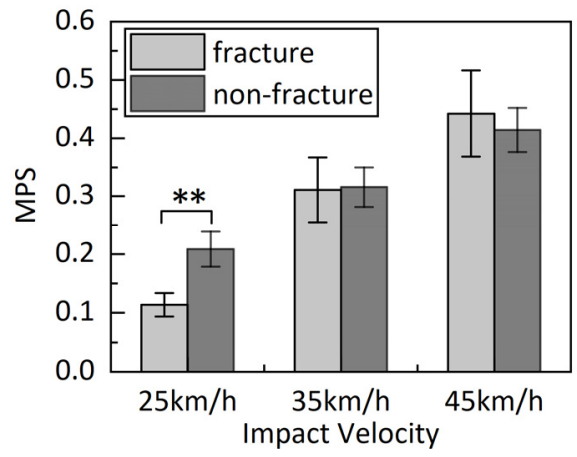

(a) frontal impact

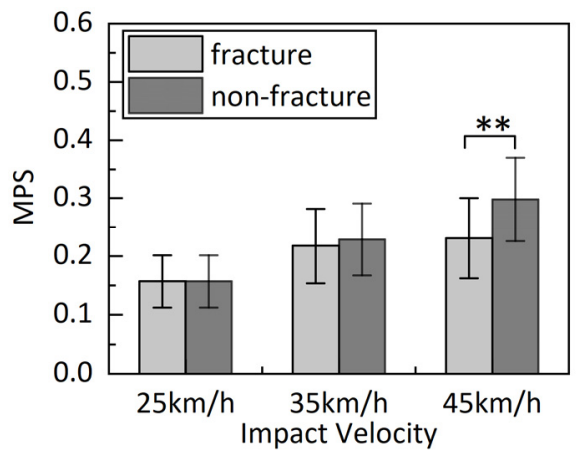

(b) parietal impact

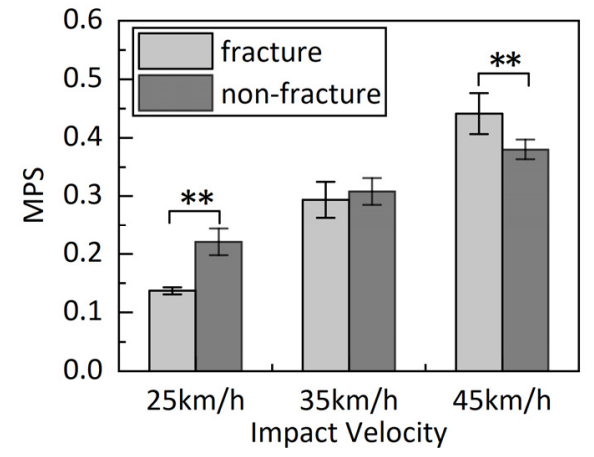

(c) occipital impact

Figure 12. Average peak MPS from the impact region of three impact models under three impact velocities. Shown are the average and standard deviations of peak MPS response of 18 elements in the selected region. Asterisks on fracture and non-fracture models indicate the significant level of skull fracture effect on MPS peaks at each velocity; * denotes significant effect, that is, $0.01<p \leq 0.05 ; * *$ denotes extremely significant effect, that is, $p \leq 0.01$. (a) frontal impact (b) parietal impact (c) occipital impact. 


\section{3. $C S D M$}

CSDM values of the white matter of the cerebrum and brainstem for models of three impact locations are illustrated in Figure 13. CSDM values of the fracture model were lower than the corresponding values of the non-fracture model. The average CSDM values and standard deviation of three impact velocities are illustrated in Figure 14. Compared with CSDM values of the non-fracture model, corresponding values of the fracture model were decreased by an average of $49.3 \%, 55.0 \%$, and $45.2 \%$ at 25,35 , and $45 \mathrm{~km} / \mathrm{h}$, respectively. In addition, significant differences could be observed for simulations at $35 \mathrm{~km} / \mathrm{h}(p=0.027)$ and $45 \mathrm{~km} / \mathrm{h}(p=0.022)$.

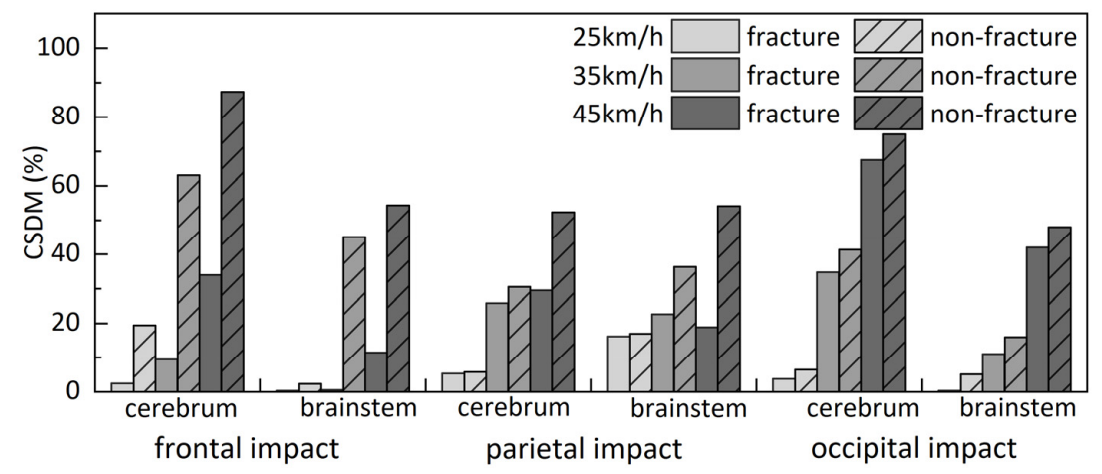

Figure 13. Comparison of cumulative strain damage measure (CSDM) between fracture and non-fracture models (strain threshold of 0.15).

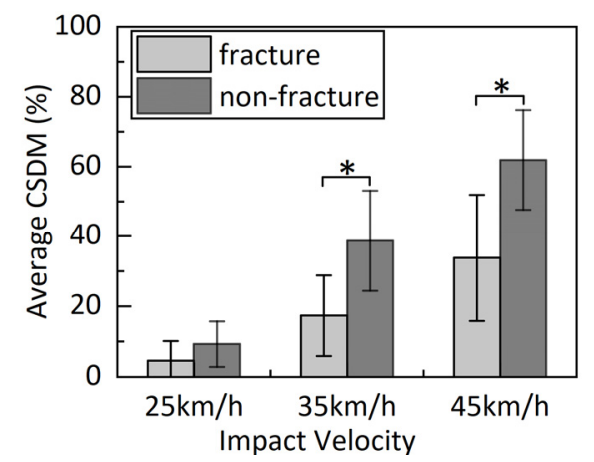

Figure 14. Comparison of average CSDM between head fracture and non-fracture models. Shown are average CSDM and standard deviation of the white matter of the cerebrum and brainstem for three impact velocities. Asterisks on fracture and non-fracture models indicate the significant level of skull fracture effect on CSDMs at each velocity; ${ }^{*}$ denotes significant effect, that is, $p \leq 0.05$.

\section{Discussion}

The objective of this study is to investigate the influence of the skull fracture on TBIs under head-ground impacts. A total of 18 head-ground impact simulations were conducted by applying the newly improved THUMS-head FE model with skull element damage modeling and the original THUMS-head FE model, while three head impact locations (frontal, parietal, and occipital regions) and three impact velocities $(25,35$, and $45 \mathrm{~km} / \mathrm{h})$ were employed. As the impact location was varied, the BrIC values of three impact models were calculated to assess whether the risk of brain injuries was consistent at the same velocity. A $50 \%$ risk of brain injury predicted by the three impact models was generally consistent at the same velocity (Figure 10). Therefore, three impact models were utilized to investigate the influence of skull fractures on brain injuries, which are suitable for this study.

As illustrated in Figure 8, different head impact locations could result in different skull fracture patterns [3,37-39]. Linear fractures in frontal [37] and occipital regions and depressed fractures in the parietal region were found at higher velocities [3], and fracture patterns were observed to be consistent 
with those commonly reported in the literature. In addition, the predicted resultant acceleration of the fracture model was lower than the corresponding value of the non-fracture model (Figure 9), suggesting that a certain amount of impact energy could be absorbed during the skull fracture [15,39].

The power of the MPS for the prediction of cerebral contusion has been confirmed in experimental studies [33]. Therefore, the MPS of two models at the impact region of the cerebrum were compared with the analysis of the influence of skull fractures on contusions in this study. For low impact velocity, the MPS values of the fracture model were significantly lower than the corresponding values of the non-fracture model, except for the parietal impact. When a small linear skull fracture occurred, the skull could still play a protective role regarding the brain tissue, and also a certain amount of impact energy could be absorbed, which could reduce the energy transferred to the brain tissue. However, for high-impact velocity, the MPS values of the fracture model were distinctly higher than the corresponding values of the non-fracture model, except for the parietal impact. The higher MPS values at the region of impact in the presence of the skull fracture model are likely induced by direct impression (Figure 11) [40]. Compared with the cerebral deformations of the frontal and occipital fracture models, a probable reason for the relatively low MPS obtained in the parietal impact of the skull fracture model at high head impact velocity was that the cerebrum suffered a relatively small deformation at the region of impact.

For all of these impact conditions, the predicted CSDM values of fracture models were lower than the corresponding values of non-fracture models. CSDM values could be reduced significantly with the appearance of skull fractures, especially for frontal and parietal impacts. Even though the appearance of a skull fracture has no significant effect on the CSDM values at low head impact velocity, the average CSDM values of the fracture models are generally relatively lower than corresponding values predicted by non-fracture models, with an average reduction of $49.3 \%$, and the results observed were consistent with those reported in Carson et al. [14] study. As previously discussed, a certain amount of energy was absorbed during the skull fracture $[15,39]$, while still being able to protect the brain. Therefore, we could deduce that the presence of skull fractures can reduce the injury risk of DBIs.

Owing to the lack of data on head trauma in traffic accidents, the impact of skull fracture on the intracranial response cannot be quantified for validity, which needs further improvement.

\section{Conclusions}

Simulation of head-ground impact models of three locations predicted MPS and CSDM values that had an effect between the fracture and non-fracture models. The influences of skull fracture on cerebral contusion and diffuse brain injury were investigated.

The results show that MPS values could be reduced significantly after skull fracture at low head impact velocity, which presents a lower risk of cerebral contusion. Conversely, the risk of cerebral contusion rises significantly after skull fracture at higher head impact velocity.

CSDM values are employed to evaluate the risk of DBIs. Overall, the predicted average values of these injury indices of the skull fracture model are lower than the corresponding values of the non-fracture model. Therefore, it was found that skull fracture significantly reduces the risk of DBIs per results obtained using current head-ground impact models.

Author Contributions: Conceptualization, L.R.; methodology, C.J.; validation, D.W.; formal analysis, X.L.; writing-original draft preparation, D.W.; writing-review and editing, L.R.; supervision, H.Y.; project administration, Y.H.; All authors have read and agreed to the published version of the manuscript.

Funding: This research was funded by the Scientific and Technological Research Program of Chongqing Municipal Commission (Grant No. KJQN201801107), Graduate Student Innovation Program of Chongqing University of Technology (Grant No. ycx20192014), and State Key Laboratory of Vehicle NVH and Safety Technology Open Foundation (Grant No. NVHSKL-201908).

Acknowledgments: The authors would like to extend special thanks to the editor and anonymous reviewers for their constructive comments and suggestions for improving the quality of this study.

Conflicts of Interest: The authors declare no conflict of interest. 


\section{References}

1. World Health Organization. Global Status Report on Road Safety. Available online: https://www.who.int/ violence_injury_prevention/road_safety_status/2015/en/ (accessed on 20 December 2019).

2. The Ministry of Public Security of the People's Republic of China. Annual Report on Road Traffic Accidents of the People's Republic of China (2017); The Ministry of Public Security of the People's Republic of China: Beijing, China, 2018.

3. Yavuz, M.S.; Aşırdizer, M.; Cetin, G.; Balci, Y.G.; Altınkök, M. The Correlation Between Skull Fractures and Intracranial Lesions Due To Traffic Accidents. Am. J. Forensic Med. Pathol. 2003, 24, 339-345. [CrossRef] [PubMed]

4. Coronado, V.G.; Xu, L.; Basavaraju, S.V.; McGuire, L.C.; Wald, M.M.; Faul, M.; Guzman, B.R.; Hemphill, J.D. Surveillance for Traumatic Brain Injury-Related Deaths-United States, 1997-2007; Morbidity and Mortality Weekly Report; Centers for Disease Control and Prevention: Washington, DC, USA, 2011; Volume 60, pp. 1-32.

5. Shang, S.; Otte, D.; Li, G.; Simms, C. Detailed assessment of pedestrian ground contact injuries observed from in-depth accident data. Accid. Anal. Prev. 2018, 110, 9-17. [CrossRef]

6. Ahmad, S.; Afzal, A.; Rehman, L.; Javed, F. Impact of depressed skull fracture surgery on outcome of head injury patients. Pak. J. Med. Sci. 2018, 34, 130-134. [CrossRef] [PubMed]

7. Faul, M.; Coronado, V. Epidemiology of traumatic brain injury. Handb. Clinic. Neurol. 2015, 127, 3-13. [CrossRef]

8. Sahoo, D.; Deck, C.; Yoganandan, N.; Willinger, R. Development of skull fracture criterion based on real-world head trauma simulations using finite element head model. J. Mech. Behav. Biomed. Mater. 2016, 57, $24-41$. [CrossRef] [PubMed]

9. Huang, J.; Peng, Y.; Yang, J.; Otte, D.; Wang, B. A study on correlation of pedestrian head injuries with physical parameters using in-depth traffic accident data and mathematical models. Accid. Anal. Prev. 2018, 119, 91-103. [CrossRef] [PubMed]

10. Yellinek, S.; Cohen, A.; Merkin, V.; Shelef, I.; Benifla, M. Clinical significance of skull base fracture in patients after traumatic brain injury. J. Clin. Neurosci. 2016, 25, 111-115. [CrossRef]

11. Adams, J.H.; Doyle, D.; Ford, I.; Gennarelli, T.A.; Graham, D.I.; McLellan, D.R. Diffuse axonal injury in head injury: Definition, diagnosis and grading. Histopathology 1989, 15, 49-59. [CrossRef]

12. Wang, Y.; Yuan, H. Diffuse Axonal Injury caused by traffic accidents in diagnosis and treatment of 46 cases. China Pract. Med. 2010, 5, 60-62. (In Chinese)

13. Jacobo, A.-M.; Mikami, K.; Lindkvist, M.; Davidsson, J.; Schick, S. Accident analysis to support the development of strategies for the prevention of brain injuries in car crashes. Accid. Anal. Prev. 2018, 117, 98-105. [CrossRef]

14. Carson, H.J. Brain trauma in head injuries presenting with and without concurrent skull fractures. J. Forensic Leg. Med. 2009, 16, 115-120. [CrossRef] [PubMed]

15. Wood, R.L.; Eames, R. Application of behavior modification in the rehabilitation of traumatically brain-injured patients. In Applications of Conditioning Theory, 1st ed.; Davey, G., Ed.; Routledge: London, UK, 1981; pp. 81-101.

16. Toyota Central R\&D Laboratories. Toyota Motor Corporation Documentation: Total Human Model for Safety (THUMS); Toyota Central R\&D Laboratories: Nagakute, Japan, 2011; pp. 26-29.

17. Watanabe, R.; Miyazaki, H.; Kitagawa, Y.; Yasuki, T. Research of collision speed dependency of pedestrian head and chest injuries using human FE model (THUMS version 4). Accid. Reconstr. J. 2012, 22, 11-43.

18. Wang, F.; Han, Y.; Wang, B.; Peng, Q.; Huang, X.; Miller, K.; Wittek, A. Prediction of brain deformations and risk of traumatic brain injury due to closed-head impact: Quantitative analysis of the effects of boundary conditions and brain tissue constitutive model. Biomech. Model. Mechanobiol. 2018, 17, 1165-1185. [CrossRef] [PubMed]

19. Ren, L.; Wang, D.; Jiang, C.; Hu, Y. Influence of Foramen Magnum Boundary Condition on Intracranial Dynamic Response Under Forehead Impact Using Human Body Finite Element Model. Int. J. Comput. Methods 2019. [CrossRef]

20. Yu, C.; Wang, F.; Wang, B.; Li, G.; Li, F. A Computational Biomechanics Human Body Model Coupling Finite Element and Multibody Segments for Assessment of Head/Brain Injuries in Car-To-Pedestrian Collisions. Int. J. Environ. Res. Public Health 2020, 17, 492. [CrossRef] 
21. Wang, F.; Yu, C.; Wang, B.; Li, G.; Miller, K.; Wittek, A. Prediction of pedestrian brain injury due to vehicle impact using computational biomechanics models: Are head-only models sufficient? Inj. Prev. 2019, 21, 102-107. [CrossRef]

22. Kimpara, H.; Nakahira, Y.; Iwamoto, M.; Miki, K.; Ichihara, K.; Kawano, S.; Taguchi, T. Investigation of anteroposterior head-neck responses during severe frontal impacts using a brain-spinal cord complex FE model. Stapp Car Crash J. 2006, 50, 509-544. [CrossRef]

23. Wood, J.L. Dynamic response of human cranial bone. J. Biomech. 1971, 4, 1-12. [CrossRef]

24. Li, Z.; Kindig, M.W.; Kerrigan, J.; Untaroiu, C.; Subit, D.; Crandall, J.R.; Kent, R.W. Rib fractures under anterior-posterior dynamic loads: Experimental and finite-element study. J. Biomech. 2010, 43, 228-234. [CrossRef]

25. Frida, A. Finite Element Modeling of Skull Fractures-material Model Improvements of the Skull Bone in the KTH FE Head Model. Master's Thesis, KTH Royal Institute of Technology, Stockholm, Sweden, 2016.

26. Cheng, Y. Head Injury Causation in Car Rollover Crashes. Ph.D. Thesis, The University of Birmingham, Birmingham, UK, 2008.

27. Highway Planning and Design Institute of the Ministry of Transport. Specifications for Design Highway Asphalt Pavement; China Communications Press: Beijing, China, 1997. (In Chinese)

28. Grünert, J.; Hardy, R.; Neal-Sturgess, C.; Joonekindt, S.; Yang, J.; Yao, J.; Baumgartner, D.; Guerra, L.; Martinez, L. Assessment of the Relevance of the Secondary (Ground) Impact and Its Influence on Jnjuries; APROSYS Document AP-SP32-010R, Deliverable D3.2.4; Nederlandse Organisation for Applied Scientific Research(TNO): Helmond, The Netherlands, 2007; pp. 14-15.

29. Simms, C.; Wood, D.P. Effects of pre-impact pedestrian position and motion on kinematics and injuries from vehicle and ground contact. Int. J. Crashworthiness 2006, 11, 345-355. [CrossRef]

30. Xu, J.; Shang, S.; Qi, H.; Yu, G.; Wang, Y.; Chen, P. Simulative investigation on head injuries of electric self-balancing scooter riders subject to ground impact. Accid. Anal. Prev. 2016, 89, 128-141. [CrossRef] [PubMed]

31. Takhounts, E.G.; Craig, M.J.; Moorhouse, K.; McFadden, J.; Hasija, V. Development of brain injury criteria (BrIC). Stapp Car Crash J. 2013, 57, 243-266. [PubMed]

32. Mao, H.; Zhang, L.; Yang, K.H.; King, A.I. Application of a finite element model of the brain to study traumatic brain injury mechanisms in the rat. Stapp Car Crash J. 2006, 50, 583-600. [PubMed]

33. Mao, H.; Yang, K.H. Investigation of brain contusion mechanism and threshold by combining finite element analysis with in vivo histology data. Int. J. Numer. Methods Biomed. Eng. 2010, 27, 357-366. [CrossRef]

34. Takhounts, E.G.; Ridella, S.A.; Hasija, V.; Tannous, R.E.; Campbell, J.; Malone, D.; Danelson, K.; Stitzel, J.; Rowson, S.; Duma, S. Investigation of traumatic brain injuries using the next generation of simulated injury monitor (SIMon) finite element head model. Stapp Car Crash J. 2008, 52, 402-432. [CrossRef]

35. Ren, L.; Baumgartner, D.; Yang, J.; Davidsson, J.; Willinger, R. Investigation of diffuse axonal injury induced by rotational acceleration via numerical reconstructions of in vivo rat head impact experiments. Int. J. Crashworthiness 2015, 20, 602-612. [CrossRef]

36. Takhounts, E.G.; Eppinger, R.H.; Campbell, J.; Tannous, R.E.; Power, E.D.; Shook, L.S. On the Development of the SIMon Finite Element Head Model. Stapp Car Crash J. 2003, 47, 107-133. [CrossRef]

37. Sahoo, D.; Deck, C.; Yoganandan, N.; Willinger, R. Anisotropic composite human skull model and skull fracture validation against temporo-parietal skull fracture. J. Mech. Behav. Biomed. Mater. 2013, 28, 340-353. [CrossRef]

38. Mao, H.; Zhang, L.; Jiang, B.; Genthikatti, V.V.; Jin, X.; Zhu, F.; Makwana, R.; Gill, A.; Jandir, G.; Singh, A.; et al. Development of a Finite Element Human Head Model Partially Validated With Thirty Five Experimental Cases. J. Biomech. Eng. 2013, 135, 111002-111015. [CrossRef]

39. Van Lierde, C.; Depreitere, B.; Sloten, J.V.; Van Auderkercke, R.; Van Der Perre, G.; Goffin, J. Skull biomechanics: The energy absorbability of the human skull frontal bone during fracture under quasi-static loading. J. Appl. Biomater. Biomech. 2003, 1, 194-199.

40. Kleiven, S. Why Most Traumatic Brain Injuries are Not Caused by Linear Acceleration but Skull Fractures are. Front. Bioeng. Biotechnol. 2013, 1. [CrossRef] [PubMed]

(C) 2020 by the authors. Licensee MDPI, Basel, Switzerland. This article is an open access article distributed under the terms and conditions of the Creative Commons Attribution (CC BY) license (http://creativecommons.org/licenses/by/4.0/). 